\title{
The preventive services use self-efficacy (PRESS) scale in older women: development and psychometric properties
}

Mini E. Jacob ${ }^{1 *}$ D, Wei-Hsuan Lo-Ciganic ${ }^{2}$, Laurey R. Simkin-Silverman', Steven M. Albert ${ }^{3}$, Anne B. Newman', Lauren Terhorst ${ }^{4}$, Joni Vander Bilt ${ }^{1}$, Janice C. Zgibor ${ }^{1}$ and Elizabeth A. Schlenk ${ }^{5}$

\begin{abstract}
Background: Preventive services offered to older Americans are currently under-utilized despite considerable evidence regarding their health and economic benefits. Individuals with low self-efficacy in accessing these services need to be identified and provided self-efficacy enhancing interventions. Scales measuring self-efficacy in the management of chronic diseases exist, but do not cover the broad spectrum of preventive services and behaviors that can improve the health of older adults, particularly older women who are vulnerable to poorer health and lesser utilization of preventive services. This study aimed to evaluate the psychometric properties of a new preventive services use self-efficacy scale, by measuring its internal consistency reliability, assessing internal construct validity by exploring factor structure, and examining differences in self-efficacy scores according to participant characteristics.
\end{abstract}

Methods: The Preventive Services Use Self-Efficacy (PRESS) Scale was developed by an expert panel at the University of Pittsburgh Center for Aging and Population Health - Prevention Research Center. It was administered to 242 women participating in an ongoing trial and the data were analyzed to assess its psychometric properties. An exploratory factor analysis with a principal axis factoring approach and orthogonal varimax rotation was used to explore the underlying structure of the items in the scale. The internal consistency of the subscales was assessed using Cronbach's alpha coefficient.

Results: The exploratory factor analysis defined five self-efficacy factors (self-efficacy for exercise, communication with physicians, self-management of chronic disease, obtaining screening tests, and getting vaccinations regularly) formed by 16 items from the scale. The internal consistency of the subscales ranged from .81 to .94 . Participants who accessed a preventive service had higher self-efficacy scores in the corresponding sub-scale than those who did not.

Conclusions: The 16-item PRESS scale demonstrates preliminary validity and reliability in measuring self-efficacy in the use of preventive services among older women. It can potentially be used to evaluate the impact of interventions designed to improve self-efficacy in the use of preventive services in community-dwelling older women.

Keywords: Self-efficacy, Preventive services, Older adults, Psychometrics

\footnotetext{
*Correspondence: mej49@pitt.edu

${ }^{1}$ Graduate School of Public Health Department of Epidemiology, University

of Pittsburgh, Pittsburgh, USA

Full list of author information is available at the end of the article
} 


\section{Background}

Despite clear guidelines set by the U.S. Preventive Services Task Force and recent legislative and policy measures intended to improve access to health care, there are significant gaps in the utilization of preventive services by older Americans [1]. Improving access to preventive services like routine disease screening and scheduled vaccinations can have substantial benefits. A uniform increase in the utilization of 9 clinical preventive services (control of hypertension, control of elevated LDL cholesterol, aspirin chemoprophylaxis, smoking cessation, colonoscopy screening, mammography screening, pap smear screening, influenza vaccination, and pneumococcal vaccination) to levels achieved by high performing health systems could prevent 50,000 to 100,000 deaths every year in the population aged less than 80 years [2]. Increasing the use of these services from current levels to $90 \%$ would also result in total savings of $\$ 3.7$ billion [3]. Closing this gap for older populations will require concerted action by the forces of public health infrastructure, community-based organizations, and aging services network. Efforts should particularly target older women who comprise $56 \%$ of this population, and are vulnerable to poorer health and lesser utilization of preventive services [4].

Strategies to improve preventive service use should include public health interventions that extend beyond clinical settings and reach people individually or collectively to enhance community capacity $[5,6]$. Such preventive health interventions are likely to be most effective if reliable and valid tools can be used to identify individuals and communities at risk for inadequate use of preventive services. An efficient method of riskidentification would include the assessment of selfefficacy in this domain. Self-efficacy, defined as individuals' assessments of their ability to perform a specific behavior successfully [7], is an important belief that can predict health behaviors [8-11]. All major theories of health behavior change incorporate self-efficacy as a major component $[12,13]$. Over the years, there has been a growing acceptance of the role of self-efficacy in modulating health behaviors and in turn positively affecting health outcomes. Research has shown that individuals with higher self-efficacy are more effective in the self-management of diabetes [14], hypertension [15], and arthritis pain [16]. High self-efficacy is also associated with better oral health [17] and better self-reported health in cardiovascular disease [18].

Self-efficacy plays an important role in determining the utilization of preventive services. It has been shown to be a strong predictive factor in a woman's decision to obtain a mammogram [19] and to be associated with the probability of obtaining a colonoscopy for colon cancer screening [20]. Interventions that improve self-efficacy have also been shown to improve preventive health behaviors, such as physical activity [21]. Besides selfefficacy, there are multiple factors that determine the use of preventive services. While health insurance and economic access may be important factors in countries like Mexico [22], in the US, where preventive services for older adults are covered by Medicare, determinants of preventive service use among older adults include gender [4], race/ethnicity [23], depressive symptoms [24], health literacy, geographic isolation [25], as well as provider recommendation [26]. Greater aging satisfaction has been shown to be associated with greater use of preventive services [27]. Further investigation is required for understanding how the different predictors including self-efficacy may interplay in the final decision to access preventive care or participate in a preventive behavior; theoretical models include self-efficacy as an intermediate factor in the relationship between health literacy and health behavior [28]. However, the paramount role of self-efficacy in undeniable; enhancing self-efficacy is crucial for behavior change [7]. Yet, despite the considerable interest in lifestyle change for preventing death and disease in the recent years, the construct of self-efficacy in a broad range of preventive behaviors has not been given due importance by health researchers and health care personnel.

Several instruments have been developed to measure general self-efficacy as well as specific self-efficacy in domains as varied as breast feeding [29], exercise [30], smoking cessation [31], peer-aggression coping, and pain [32]. Self-efficacy in different domains of functioning may not correlate; therefore, it is important to develop self-efficacy measurement tools in specific domains [33]. Scales measuring self-efficacy in the management of chronic diseases exist [34], but do not cover the broad spectrum of preventive services and preventive behaviors that can improve the health of older adults in general and older women in particular. For example, the Stanford Chronic Disease Self-efficacy Scale assesses an individual's confidence in self-managing disease symptoms, pain, and emotional distress caused by disease, but does not include items pertaining to self-efficacy for smoking cessation, cancer screening or obtaining immunizations. An instrument measuring self-efficacy in a wide range of preventive behaviors would be very useful in identifying high-risk individuals and may also help evaluate the effect of interventions designed to improve self-efficacy in this domain.

The University of Pittsburgh Center for Aging and Population Health - Prevention Research Center (CAPH-PRC) developed the Preventive Service Use SelfEfficacy (PRESS) Scale based on important areas of disease prevention for this age group known as the "10 Keys" ${ }^{\text {"м }}$ to Healthy Aging ("10 Keys"TM). The "10 Keys" ${ }^{\text {”м }}$, 
identified by experts in aging research at the CAPHPRC, using evidence from epidemiological, clinical and lab studies, includes the following - control of (1) blood pressure, (2) glucose, and (3) low-density lipoprotein cholesterol (LDL-C), (4) smoking cessation, (5) cancer screenings, (6) immunizations, (7) physical activity, (8) musculoskeletal health, (9) social contact, and (10) combating depression. Seven of these keys have been listed by the National Commission on Prevention Priorities among the top 20 evidence-based clinical preventive services with the biggest impact on the health of the U.S. population [3]. A behavioral activation program based on the "10 Keys" has been found to be effective in improving diverse indicators of preventive health $[35,36]$. The need for promotion and further evaluation of this evidence-based and effective program as an intervention to improve self-efficacy in preventive services use among older adults in the community led to the development of the PRESS scale.

For developing the scale, an expert panel consisting of 5 research faculty at the CAPH-PRC identified 21 questions pertaining to self-efficacy in preventive service use and preventive behaviors important for older adults. The initial item pool was generated based on a review of the literature and review of scales available in this domain. The expert panel developed 13 items to address each aspect of the "10 Keys" ${ }^{\text {"xx }}$. The remaining eight items were adapted from the Stanford Patient Education Research Center Chronic Disease Self-efficacy scale and assessed self-efficacy for exercising regularly, getting information about disease and disability prevention from community resources, and communicating with physicians [37]. A Likert scale response format was employed with graded scores ranging from 1 to 10 , with 1 indicating "not at all confident" and 10 indicating "totally confident". The 10 point scale was chosen considering the educational level of the participants and the success of other 10 point scales used in other studies conducted at the CAPHPRC. Participants with higher scale scores are defined as having higher self-efficacy, that is, they have greater confidence in their ability to perform the indicated preventive behaviors.

In this study, we aimed to assess the internal construct validity of this scale by exploring its factor structure and examine differences in self-efficacy scores according to participant characteristics. We hypothesized that participants who reported participation in a certain preventive behavior would have higher self-efficacy scores for items pertaining to that behavior whereas participants who had a certain chronic disease would have lower selfefficacy scores for corresponding items compared to those who did not have the disease. We also aimed to assess the internal consistency reliability of this new scale. Our investigation was performed to show that the new scale can be used in community settings to identify women in need of strategies to enhance self-efficacy for preventive service use and adopt preventive behaviors.

\section{Methods}

\section{Setting and sample}

We conducted secondary analysis of baseline data from 242 women participating in a prevention trial integrating the Arthritis Foundation Exercise Program (AFEP) with the "10 Keys" ${ }^{\text {" }}$ program, a result of the collaboration between the Arthritis Foundation of Pennsylvania and the CAPH-PRC. This cluster randomized controlled trial is evaluating the effectiveness of the integrated program (AFEP + "10 Keys" ${ }^{m \text { m }}$ ) in improving arthritis symptoms, self-efficacy, indicators of preventive services use, and risk factors for disability and chronic disease compared to the AFEP alone. A pilot evaluation of this project demonstrated feasibility as well as improvements in some health behaviors [38]. Participants in the trial $(n=462)$ were located at 49 different community sites and were recruited locally by site personnel and screened for eligibility by study personnel. Forty-six sites were located in Allegheny County, and three sites were located in Washington, Mercer, and Fayette counties, respectively. The sites included eight churches, two YMCA sites, eight subsidized housings, four community centers, 13 senior centers, four fitness clubs or centers, six residential facilities, and four libraries. Participants were eligible for the research study if they were age 50 years or older and did not have medical contraindications including oxygen use, hospitalization for a cardiac event, or major surgery in the previous six months.

For this analysis, we included 242 women who completed the PRESS scale at their baseline visit, between April 2012 and April 2014. The trial also included men but we chose to restrict this study to women as the presence of gender-specific questions in the scale demanded separate evaluations for men and women and we did not have an adequate sample for evaluating men separately. We also excluded participants who did not respond to one or more items on the scale (112 out of 354 women who were administered the PRESS scale). Participants completed the self-efficacy scale as part of a larger battery of self-administered items (including the Western Ontario and McMaster Universities Arthritis Index (WOMAC)) at the intervention site in the community or at home. Written informed consent was obtained from all participants in the study. The study was approved by the University of Pittsburgh Institutional Review Board and the Ethics committee.

For this analysis, we excluded the item assessing selfefficacy for smoking cessation because $92.8 \%$ of the participants did not smoke. We also excluded one item 
which was specific only to men (i.e., how confident are you that you can get advice on prostate cancer screening?). Our final analysis sample included 242 women and 19 selfefficacy items.

\section{Statistical analysis}

All analyses were performed using SPSS version 20 (SPSS Inc., Chicago, IL) and SAS software, version 9.3 (SAS Institute Inc, Cary, North Carolina). Appropriate descriptive statistics (mean, standard deviation, median, range, frequency or percentage) were employed to summarize participant characteristics and self-efficacy data. Inter-item correlations were calculated using Pearson correlation coefficients to investigate the interrelationships and possible clustering among the items. An exploratory factor analysis (EFA) with principal axis factoring (PAF) extraction and orthogonal varimax rotation (factors assumed to be uncorrelated) was used to explore the underlying structure of the scale. The PAF method searches for the fewest number of factors that can explain the variance in the item set [39], and is preferred over principal component analysis because it provides an extraction of the shared variance among the items
Table 1 Participants characteristics of 242 women participants

\begin{tabular}{ll}
\hline Variable $^{a}$ & Descriptive statistics \\
\hline Mean age (SD, range) & $72.2(7.4,54-90)$ \\
Race (\%) & $188(79.4)$ \\
White & $43(18.1)$ \\
Black & $6(2.5)$ \\
Other & \\
Education (\%) & $83(34.7)$ \\
High school or less & $156(65.3)$ \\
Some college or higher & $206(86.2)$ \\
Diagnosis of arthritis (\%) & \\
Pre-program exercise routine (\%) & $28(12.1)$ \\
Never exercise & $131(56.7)$ \\
Exercise sometimes & $72(31.0)$ \\
Exercise regularly &
\end{tabular}

${ }^{a}$ Number of missing values in race $(n=5)$, education $(n=3)$, diagnosis of arthritis $(n=3)$, pre-program exercise routine $(n=11)$

Table 2 Item characteristics of the 19-item preventive services use self-efficacy scale $(N=242)$

How confident are you that you can..

1. do gentle exercises for muscle strength 2-3 times/week?

2. do gentle exercises for flexibility?

3. do moderate physical activity for at least $21 / 2 \mathrm{~h} /$ week?

4. exercise without making symptoms worse?

5. get information about disease and disability prevention from community resources?

6. ask your doctor things about health issues that concern you?

7. discuss openly with your doctor any personal problems that may be related to your health?

8. work out differences with your doctor when they arise?

9. continue to do the things you like to do with friends and family?

10. keep from feeling sad or down in the dumps?

11. take an active role to manage your systolic blood pressure?

12. take an active role to manage your blood glucose (sugar) level?

13. take an active role to manage your LDL cholesterol level?

14. get a colonoscopy test?

15. get an influenza vaccine?

16. get a pneumonia vaccine?

17. get a Mammogram? (women specific)

18. get a Pap test and pelvic exam? (women-specific)

19. get a bone density test? (women-specific)

\begin{tabular}{|c|c|c|c|}
\hline $\begin{array}{l}\text { Mean } \\
\text { (SD) }\end{array}$ & $\begin{array}{l}\text { Median } \\
\text { (IQR) }\end{array}$ & $\begin{array}{l}\% \text { of minimum scores } \\
(1-2)\end{array}$ & $\begin{array}{l}\% \text { of maximum score } \\
(9-10)\end{array}$ \\
\hline $8.7(1.9)$ & $10.0(2)$ & 2.1 & 70.2 \\
\hline $8.7(1.8)$ & $10.0(2)$ & 1.2 & 67.4 \\
\hline $6.4(3.3)$ & $7.0(6)$ & 20.7 & 35.1 \\
\hline $7.5(2.5)$ & $8.0(4)$ & 4.1 & 42.2 \\
\hline $7.5(2.7)$ & $8.0(4)$ & 7.4 & 46.3 \\
\hline $9.3(1.4)$ & $10.0(1)$ & 0.4 & 82.6 \\
\hline $9.1(1.6)$ & $10.0(1)$ & 0.8 & 77.4 \\
\hline $9.0(1.7)$ & $10.0(1)$ & 1.2 & 76.5 \\
\hline $8.9(1.8)$ & $10.0(2)$ & 0.8 & 70.6 \\
\hline $8.1(1.9)$ & $8.5(3)$ & 1.2 & 50.0 \\
\hline $8.9(1.4)$ & $9.0(2)$ & 0.4 & 67.8 \\
\hline $8.7(1.6)$ & $9.0(2)$ & 0.4 & 65.7 \\
\hline $8.5(1.7)$ & $9.0(2)$ & 0.8 & 62.0 \\
\hline $9.2(2.1)$ & $10.0(0)$ & 3.7 & 83.1 \\
\hline $9.4(1.9)$ & $10.0(0)$ & 4.1 & 90.9 \\
\hline $9.5(1.8)$ & $10.0(0)$ & 2.9 & 89.7 \\
\hline $9.6(1.3)$ & $10.0(0)$ & 1.2 & 92.2 \\
\hline $9.5(1.5)$ & $10.0(0)$ & 1.7 & 88.4 \\
\hline $9.4(1.8)$ & $10.0(0)$ & 2.9 & 86.4 \\
\hline
\end{tabular}


Table 3 Factor loadings and total variance explained from the factor structure matrix (Varimax rotation) for the 16 Items in the preventive services use self-efficacy scale

\begin{tabular}{|c|c|c|c|c|c|}
\hline \multirow[b]{2}{*}{ Item by factor } & \multicolumn{5}{|c|}{ Factor } \\
\hline & I & $\|$ & III & IV & V \\
\hline \multicolumn{6}{|l|}{ How confident are you that you can... Factor I. Self-efficacy for Exercise } \\
\hline 1. do gentle exercises for muscle strength 2-3 times/week? & .87 & & & & \\
\hline 2. do gentle exercises for flexibility? & .83 & & & & \\
\hline 3. do moderate physical activity for at least $21 / 2 \mathrm{~h} /$ week? & .63 & & & & \\
\hline 4. exercise without making symptoms worse? & 67 & & & & \\
\hline \multicolumn{6}{|l|}{ Factor II. Self-efficacy for Communication with Physicians } \\
\hline 6. ask your doctor things about health issues that concern you? & & .86 & & & \\
\hline 7. discuss openly with your doctor any personal problems that may be related to your health? & & .92 & & & \\
\hline 8. work out differences with your doctor when they arise? & & .88 & & & \\
\hline \multicolumn{6}{|l|}{ Factor III. Self-efficacy for Self-Management of Chronic Disease } \\
\hline 11. take an active role to manage your systolic blood pressure? & & & .76 & & \\
\hline 12. take an active role to manage your blood glucose (sugar) level? & & & .86 & & \\
\hline 13. take an active role to manage your LDL cholesterol level? & & & .81 & & \\
\hline \multicolumn{6}{|l|}{ Factor IV. Self-efficacy for Obtaining Screening Tests } \\
\hline 14. get a colonoscopy & & & & .55 & \\
\hline 17. get a mammogram & & & & .70 & \\
\hline 18. get a Pap test and pelvic exam & & & & .85 & \\
\hline 19. get a bone density test & & & & .52 & \\
\hline \multicolumn{6}{|l|}{ Factor V. Self-efficacy for Getting Vaccinations Regularly } \\
\hline 15. get an influenza vaccine? & & & & & .72 \\
\hline 16. get a pneumonia vaccine? & & & & & .89 \\
\hline$\%$ of Variance & 15.5 & 14.8 & 12.9 & 10.5 & 9.8 \\
\hline Cumulative \% & 15.5 & 30.3 & 43.2 & 53.7 & 63.5 \\
\hline
\end{tabular}

Note: Three items did not load on any of 5 factors: item 5 (get information about disease and disability prevention from community resources?), item 9 (continue to do the things you like to do with friends and family?), and item 10 (keep from feeling sad or down in the dumps?)

(rather than a combination of unique and shared variance) [40]. Although we performed both oblique and orthogonal rotations, our results were very similar. We chose to report the orthogonal results, which are parsimonious, simpler to understand, and more replicable [41]. Kaiser-Meyer-Olkin measure [42] and Bartlett's test of sphericity [43] were used to evaluate sampling adequacy and the appropriateness of conducting PAF. A Kaiser-Meyer-Olkin value of $\geq 0.60$ was used to indicate an adequate sample and a significant Bartlett's test was used to indicate appropriateness of PAF. In the PAF solution, the Cattell's scree test and the total variance explained were examined to determine the number of underlying factors in the PRESS Scale and factors with eigenvalues greater than 1.0 were extracted. In the extraction phase, items that met a minimum factor loading of .50 were considered relevant [44]. Items with loading $\geq .50$ on more than one factor were considered cross-loading items [45]. If the items did not load on any factor at the cut-off of .50 , the item was flagged for further investigation.

After the EFA was conducted, a parallel analysis was performed to determine and confirm the appropriate number of factors to retain [46]. A random dataset with the same sample size $(n=242)$ and number of variables $(n=19)$ as the original dataset was first generated with 1000 repetitions. Next, the mean and $95^{\text {th }}$ percentile of each eigenvalue of the random data was calculated. Factors in the PAF results with eigenvalues larger than the mean eigenvalues of the parallel analysis were retained [46].

Subscales were interpreted and labeled by the research team based on the factors identified by this PAF approach. Mixed models were used to take into account the clustered effect of data with patients nested in program sites (i.e., program sites were entered as random effects using SAS PROC MIXED and GLIMIX) and to test differences in base line characteristics and self- 


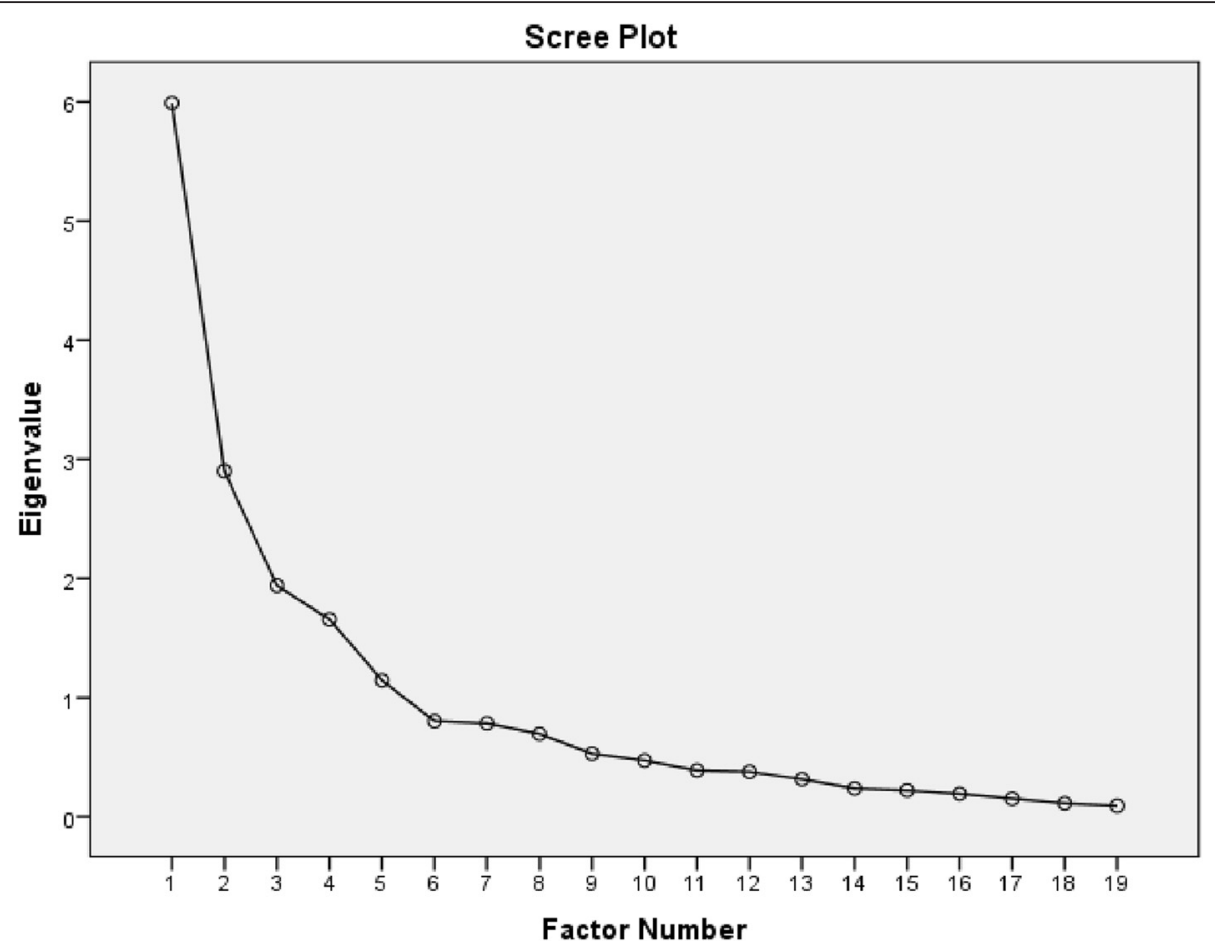

Fig. 1 Scree plot of the exploratory factor analysis of the PRESS scale

efficacy in the use of preventive services between subgroups. Finally, internal consistency of the subscales was assessed by using Cronbach's alpha coefficient, a reliability index that estimates the internal consistency of the items in the instrument [47]. Alpha coefficients and itemtotal correlations were examined. An alpha coefficient of .80 or higher was considered to be acceptable [48].

\section{Results}

\section{Sample characteristics}

Among 242 women participants, the mean age was 72 years, $79 \%$ were white and $18 \%$ were black, $65 \%$ had some college or higher education, $86 \%$ had a selfreported diagnosis of arthritis, and $31 \%$ reported exercising regularly before the program started (Table 1).

\section{Item characteristics}

The item characteristics of the PRESS Scale are summarized in Table 2. Mean scores of the PRESS scale items varied from 6.4 to 9.6 , with standard deviations varying from 1.3 to 3.3 .

\section{Exploratory factor analysis}

Prior to performing the exploratory factor analysis, the suitability of the data for factor analysis was assessed. The inter-item correlations varied from .009 (item 13: take an active role to manage your LDL cholesterol level and item 15: get an influenza vaccination) to .90 (item 1: do gentle exercises for muscle strength and item 2: do gentle exercise for flexibility). The correlation matrix was factorable because all items correlated $\geq .30$ with at least three other items in the matrix. In addition, a Kaiser-Meyer-Olkin measure of sampling adequacy of .81 and Bartlett's test of sphericity $(p<.001)$ also suggested that the initial extraction process could be continued. The PAF analysis of the PRESS Scale among 242 subjects who answered all the questions suggested five underlying factors with eigenvalues from 1.10 to 6.0.

Table 3 shows the PAF results with orthogonal varimax rotation. There were no cross-loadings, and the factor loadings varied between .52 and .92 . The Scree plot (Fig. 1) indicated a 5 factor solution. Five factors were interpreted and labeled "Factor I: Self-efficacy for Exercise Subscale (items 1, 2, 3 and 4)", "Factor II: Self-efficacy for Communication with the Physician Subscale (items 6, 7, and 8)", "Factor III: Self-efficacy for Self-Management of Chronic Disease Subscale (items 11, 12, and 13)", "Factor IV: Self-efficacy for Obtaining Screening Tests Subscale (item 14, 17, 18 and 19)" and "Factor V: Self-efficacy for Getting Vaccinations Regularly Subscale (items 15 and 16)". These factors explained $64 \%$ of the total variance in the rotated PAF results. The item communalities, which provide information on how much item 
variance is explained by the extracted factors, ranged in value between .22 (item 5) to .87 (item 7). Three items (item 5, 9, and 10) did not have loadings at the .50 value on any factors (highest factor loading ranged from .32 to .47). These items also had the lowest communalities $(.22, .35, .51$, respectively), and were flagged for further investigation and discussion.

To ensure the robustness of these factors, the items (items 5, 9, and 10) with lowest communalities were removed from the final factor pattern matrix and yielded similar results (data not shown). Similar findings were observed from the oblique promax rotation (data not shown). The parallel analysis also supported a five-factor solution.

\section{Self-efficacy and participant characteristics}

As shown in Table 4, women with arthritis had a lower score in the "Self-efficacy for Exercise Subscale" than those without arthritis $(30.8 \pm 7.9$ vs. $36.4 \pm 4.2, p=<.001)$. Older women who exercised regularly compared to those who did not exercise regularly had higher scores in the "Self-efficacy for Exercise Subscale" (33.9 \pm 6.6 vs. $26.9 \pm$ 9.6, $p=.004)$. Older women with self-reported hypertension ( $25.7 \pm 4.6$ vs. $27.1 \pm 3.8, p=.02)$ or hypercholesterolemia $(25.5 \pm 4.6$ vs. $27.1 \pm 4.0, p=.006)$ had lower scores in the "Self-efficacy for Self-Management of Chronic Disease Subscale" than those without these chronic disorders. Women who received flu shots regularly $(19.7 \pm 1.3$ vs. $16.2 \pm 6.0, p<.0001)$ or a pneumonia shot $(19.4 \pm 2.1 \mathrm{vs}$.

Table 4 Preventive services use self-efficacy subscales among different subgroups

\begin{tabular}{|c|c|c|c|}
\hline Factors or self-efficacy subscales (Number of items ${ }^{a}$ ) & $\mathrm{N}$ & Mean (SD) & Median (Range, IQR) \\
\hline \multicolumn{4}{|l|}{ Self-efficacy for Exercise (4) } \\
\hline \multicolumn{4}{|l|}{ By diagnosis of arthritis } \\
\hline Yes & 206 & $30.8(7.9)^{* * * *}$ & $32.0(6-40,10)$ \\
\hline No & 27 & $36.4(4.2)$ & $37.0(24-40,6)$ \\
\hline \multicolumn{4}{|l|}{ By pre-program exercise routine } \\
\hline Never exercise & 28 & $26.9(9.6)^{* * *}$ & $29.0(6-40,14.5)$ \\
\hline Exercise sometimes & 131 & $30.9(7.4)$ & $32.0(8-40,11)$ \\
\hline Exercise regularly & 72 & $33.9(6.6)$ & $36.0(11-40,9.5)$ \\
\hline \multicolumn{4}{|l|}{ Self-efficacy for Self-management of Chronic Disease (3) } \\
\hline \multicolumn{4}{|l|}{ By self-reported hypertension } \\
\hline Yes & 165 & $25.7(4.6)^{*}$ & $27.0(3-30,7)$ \\
\hline No & 77 & $27.1(3.8)$ & $28.0(12-30,4)$ \\
\hline \multicolumn{4}{|l|}{ By self-reported diabetes } \\
\hline Yes & 56 & $25.8(4.5)$ & $27.5(14-30,7)$ \\
\hline No & 186 & $26.2(4.4)$ & $27.0(3-30,6)$ \\
\hline \multicolumn{4}{|l|}{ By self-reported hypercholesterolemia } \\
\hline Yes & 136 & $25.5(4.6)^{* *}$ & $26.5(3-30,7)$ \\
\hline No & 99 & $27.1(4.0)$ & $29.0(12-30,5)$ \\
\hline \multicolumn{4}{|l|}{ By numbers of comorbidities } \\
\hline$>3$ & 111 & $26.0(4.1)$ & $27.0(14-30,7)$ \\
\hline$\leq 3$ & 131 & $26.2(4.6)$ & $27.0(3-30,6)$ \\
\hline Factors or Self-Efficacy Subscales (Number of items ${ }^{\mathrm{a}}$ ) & N & Mean (SD) & Median (Range, IQR) \\
\hline \multicolumn{4}{|l|}{ Self-efficacy for Getting Vaccinations Regularly (2) } \\
\hline \multicolumn{4}{|l|}{ By having a flu shot in the last year at baseline } \\
\hline Got a flu shot in the last year & 189 & $19.7(1.3)^{* * * *}$ & $20.0(7-20,0)$ \\
\hline Did not get a flu shot in last year & 51 & $16.2(6.0)$ & $20.0(2-20,7)$ \\
\hline \multicolumn{4}{|l|}{ By having a pneumonia shot at baseline } \\
\hline Had a pneumonia shot previously & 185 & $19.4(2.1)^{* * * *}$ & $20.0(2-20,0)$ \\
\hline Never had a pneumonia shot & 46 & $16.7(5.8)$ & $20.0(2-20,4)$ \\
\hline
\end{tabular}

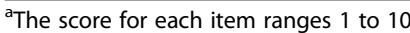

${ }^{*}: P<.05,{ }^{* *}: P<.01,{ }^{* * *}: P<.001,{ }^{* * * *}: P<.0001$ 
Table 5 Internal consistency and factor correlations of the preventive services use self-efficacy subscales $(N=242)^{a}$

\begin{tabular}{|c|c|c|c|c|c|c|c|}
\hline \multirow[t]{2}{*}{ Factors or self-efficacy subscales (Numbers of items) } & \multirow{2}{*}{$\begin{array}{l}\text { Cronbach's } \\
\text { alpha }\end{array}$} & \multirow{2}{*}{$\begin{array}{l}\text { Mean } \\
\text { (SD) }\end{array}$} & \multirow{2}{*}{$\begin{array}{l}\text { Median } \\
\text { (Range, IQR) }\end{array}$} & \multicolumn{4}{|c|}{ Factor } \\
\hline & & & & $\overline{1}$ & $\|$ & III & IV \\
\hline Factor I: Self-efficacy for Exercise (4) & .86 & $31.4(7.9)$ & $33.0(4-40,11)$ & & & & \\
\hline Factor II: Self-efficacy for Communication with Physicians (3) & .94 & $27.5(4.4)$ & $30.0(4-30,3)$ & .28 & & & \\
\hline Factor III: Self-efficacy for Self -management of Chronic Disease (3) & .89 & $26.1(4.4)$ & $27.0(3-30,6)$ & .37 & .34 & & \\
\hline Factor IV: Self-efficacy for Obtaining Screening Tests (4) & .81 & $37.7(5.3)$ & $40.0(4-40,2)$ & .15 & .21 & .28 & \\
\hline Factor V: Self-efficacy for Getting Vaccinations Regularly (2) & .83 & $18.9(3.3)$ & $20.0(2-20,0)$ & .11 & .20 & .11 & .53 \\
\hline
\end{tabular}

$I Q R$ Interquartile range

${ }^{a}$ Higher number indicates higher self-efficacy (range: 1-10 for each item)

$16.7 \pm 5.8, p<.0001$ ) had higher scores in the "Self-efficacy for Getting Vaccinations Regularly Subscale" than those who did not. The stratification analyses found no difference in the five subscales by race, and education (data not shown).

\section{Internal consistency and correlations between subscales}

Table 5 presents the descriptive statistics between factor correlations and Cronbach's alpha coefficients for the five generated subscales (corresponding to Factors I to $\mathrm{V}$ ). The internal consistency ranged from .81 to .94. All PRESS subscales demonstrated good internal consistency. The correlations among the subscales ranged from .11 to .53 (Table 5). The item-total correlations were high for all items within the subscales: "Self-efficacy for Exercise (.81 to .84)", "Self-efficacy for Communication with Physicians (.93 to .95)", "Self-efficacy for Self-management of Chronic Disease (.88 to .93)", "Self-efficacy for Obtaining Screening Tests (.73 to .83)", and "Self-efficacy for Getting Vaccinations Regularly (.91 to .93)".

\section{Discussion}

We identified a five-factor structure with good internal consistency in the PRESS scale among older women participating in a community-based cluster randomized trial. These five factors were "Self-efficacy for Exercise","Self-efficacy for Communication with Physicians", "Self-efficacy for Self-management of Chronic Disease", "Self-efficacy for Obtaining Screening Tests", and "Selfefficacy for Getting Vaccinations Regularly". Self -administration of this scale was found to be acceptable and feasible among older women in community settings.

From the original 19 items that underwent factor analysis, we identified a five-factor structure consisting of 16 items. The three items that did not load adequately dealt with self-efficacy in preventing depression, maintaining social contact, and obtaining information regarding disease and disability prevention. These items, which had been added to the scale to represent multiple methods of prevention, performed poorly as elements of this instrument and results indicated that these items need to be removed from the PRESS scale. This decision does not indicate that these items represent less important prevention methods, but that they are not statistically relevant to form a factor or subscale in this model of selfefficacy for the use of preventive services. Preventing depression and maintaining social contact may not be perceived as a 'preventive service or behavior' that needs to be actively accessed (as opposed to exercise which is often perceived as one) and could be the reason why it did not become part of the structure of the final scale. Similarly, obtaining information regarding disease and disability prevention from community resources seems to be part of a self-efficacy construct distinct from that of routine preventive services use by older women.

Five subscales in the final PRESS scale showed good internal consistency, indicating the reliability of this scale. The high item-total correlations indicate that the score on each item is consistent with the averaged score for the other questions, implying that all the items are integral to the scale and represent the same construct. Subgroups with a particular chronic disease (hypertension, hypercholesterolemia, and arthritis) had lower selfefficacy subscale scores for accessing preventive services relevant to the disease and those who were accessing a preventive service (flu shot, pneumonia shot) had higher self-efficacy scores in that subscale, providing further support for the construct validity of the 16-item PRESS scale.

Our study has some limitations. Firstly, our sample consisted mostly of older white women, which may limit generalizability of our results to other populations (e.g., African Americans). Secondly, the self-efficacy questions were asked alongside questions on preventive behaviors, but this is likely to have resulted in more accurate selfefficacy reporting than a reporting bias. In future, we propose to do confirmatory studies with more diverse samples to verify our results and explore the need for additional items to strengthen the scale. Other potential future analyses may focus on the ability of the PRESS scale to identify high-risk individuals in need of improving self-efficacy in preventive behaviors and the use of preventive services. 
To our knowledge, the PRESS scale is the first instrument developed to measure self-efficacy in a wide range of preventive behaviors and preventive services use among older women. Older adults are a high risk for disease and disability and it is important to improve access to, and utilization of, all proven prevention methods that support healthy aging and a good quality of life. Scales that measure self-efficacy in the management of specific chronic diseases do not capture this self-efficacy domain comprehensively. Given that older adults are likely to have multiple chronic conditions and impairments, this multi-pronged measure would provide consolidated information on the broad set of prevention strategies relevant to the health of older adults. The five self-efficacy subscales identified in the EFA represent crucial factors in the prevention of morbidity and mortality. Compared to the Stanford scale which evaluates self-efficacy in the management of chronic diseases, the PRESS scale is more comprehensive and specific for evaluating self-efficacy in the use of preventive services among older women. Given the current evidence and ongoing policy emphasis, the PRESS scale may serve as an important tool to identify older women with low selfefficacy in the use of preventive services and to evaluate related interventions.

\section{Conclusions}

The 16-item PRESS scale demonstrated preliminary evidence of being a valid and reliable tool to measure self-efficacy in the use of preventive services among older women. It is acceptable and feasible for administration in community settings and can potentially be used to evaluate the impact of interventions designed to improve self-efficacy in the use of preventive services in community-dwelling older women.

\section{Abbreviations}

PRESS: Preventive services use self-efficacy; CAPH-PRC: Center for aging and population health - prevention research center; LDL-C: Low-density lipoprotein cholesterol; AFEP: Arthritis foundation exercise program; EFA: Exploratory factor analysis; PAF: Principal axis factoring.

\section{Competing interests}

The authors declare that they have no competing interests.

\section{Authors' contributions}

MEJ participated in the design of the study, interpreted results, drafted the manuscript and revised it. WL participated in the design of the study, performed the statistical analysis, interpreted results, helped draft the manuscript and revised it. LRS interpreted results and revised the manuscript. SMA interpreted results and revised the manuscript. ABN obtained funding, interpreted results and revised the manuscript. LT participated in the design of the study, performed the statistical analysis, interpreted results, and revised the manuscript. JV interpreted results and revised the manuscript. JCZ conceived the study, participated in its design, interpreted results, and revised the manuscript. EAS conceived the study, participated in its design, interpreted results, and revised the manuscript. All authors contributed to revising the manuscript critically for important intellectual content. All authors read and approved the final manuscript.

\section{Acknowledgements}

This work was supported by the Centers for Disease Control, under grant numbered U48 DP001918 Prevention Research Centers.

\section{Author details}

${ }^{1}$ Graduate School of Public Health Department of Epidemiology, University of Pittsburgh, Pittsburgh, USA. ${ }^{2}$ College of Pharmacy Department of Pharmacy, University of Arizona, Tucson, USA. ${ }^{3}$ Graduate School of Public Health Department of Behavioral and Community Health Sciences, University of Pittsburgh, Pittsburgh, USA. ${ }^{4}$ School of Health and Rehabilitation Sciences Department of Occupational Therapy, University of Pittsburgh, Pittsburgh, USA. ${ }^{5}$ School of Nursing Department of Health and Community Systems, University of Pittsburgh, Pittsburgh, USA.

Received: 23 September 2015 Accepted: 11 February 2016

Published online: 20 February 2016

\section{References}

1. Centers for Disease Control and Prevention AoA, Agency for Healthcare Research and Quality, and, Services CfMaM. Enhancing Use of Clinical Preventive Services Among Older Adults. 2011

2. Farley TA, Dalal MA, Mostashari F, Frieden TR. Deaths preventable in the U.S. by improvements in use of clinical preventive services. Am J Prev Med. 2010;38(6):600-9.

3. Maciosek MV, Coffield AB, Flottemesch TJ, Edwards NM, Solberg LI. Greater use of preventive services in U.S. health care could save lives at little or no cost. Health Aff. 2010;29(9):1656-60.

4. Cameron KA, Song J, Manheim LM, Dunlop DD. Gender disparities in health and healthcare use among older adults. J Women's Health (2002). 2010;19(9):1643-50.

5. Frieden TR. A framework for public health action: the health impact pyramid. Am J Public Health. 2010;100(4):590-5.

6. Krist AH, Shenson D, Woolf SH, Bradley C, Liaw WR, Rothemich SF, Slonim A, Benson W, Anderson LA: Clinical and community delivery systems for preventive care: an integration framework. Am J Prev Med. 2013;45(4):508-16.

7. Bandura A. Self-efficacy: toward a unifying theory of behavioral change. Psychol Rev. 1977:84(2):191-215.

8. O'Leary A. Self-efficacy and health. Behav Res Ther. 1985;23(4):437-51.

9. Kavookjian J, Berger BA, Grimley DM, Villaume WA, Anderson HM, Barker KN. Patient decision making: strategies for diabetes diet adherence intervention. RSAP. 2005;1(3):389-407.

10. Prochaska JO, DiClemente CC, Velicer WF, Ginpil S, Norcross JC Predicting change in smoking status for self-changers. Addict Behav. 1985;10(4):395-406

11. DuCharme KA, Brawley LR. Predicting the intentions and behavior of exercise initiates using two forms of self-efficacy. J Behav Med. 1995:18(5):479-97.

12. Rosenstock IM, Strecher VJ, Becker MH. Social learning theory and the Health Belief Model. Health Educ Q. 1988;15(2):175-83.

13. Bui $L$, Mullan B, McCaffery K. Protection motivation theory and physical activity in the general population: a systematic literature review. Psychol Health Med. 2013;18(5):522-42.

14. Sarkar U, Fisher L, Schillinger D. Is self-efficacy associated with diabetes self-management across race/ethnicity and health literacy? Diabetes Care. 2006;29(4):823-9.

15. Warren-Findlow J, Seymour RB, Brunner Huber LR. The association between self-efficacy and hypertension self-care activities among African American adults. J Community Health. 2012;37(1):15-24.

16. Somers TJ, Wren AA, Shelby RA. The context of pain in arthritis: self-efficacy for managing pain and other symptoms. Curr Pain Headache Rep. 2012;16(6):502-8.

17. Lee JY, Divaris K, Baker AD, Rozier RG, Vann Jr WF. The relationship of oral health literacy and self-efficacy with oral health status and dental neglect. Am J Public Health. 2012;102(5):923-9.

18. Sarkar U, Ali S, Whooley MA. Self-efficacy and health status in patients with coronary heart disease: findings from the heart and soul study. Psychosom Med. 2007;69(4):306-12.

19. Tolma EL, Reininger BM, Ureda J. What predicts a Cypriot woman's decision to obtain or not obtain a screening mammogram? Implications for the 
promotion of screening mammography in Cyprus. Eur J Cancer Prev. 2006 15(2):149-57.

20. Halbert CH, Barg FK, Guerra CE, Shea JA, Armstrong K, Ferguson M, Weathers B, Coyne J, Troxel AB. Cultural, economic, and psychological predictors of colonoscopy in a national sample. J Gen Intern Med. 2011; 26(11):1311-6.

21. Lee LL, Arthur A, Avis M. Using self-efficacy theory to develop interventions that help older people overcome psychological barriers to physical activity: a discussion paper. Int J Nurs Stud. 2008:45(11):1690-9.

22. Pagan JA, Puig A, Soldo BJ. Health insurance coverage and the use of preventive services by Mexican adults. Health Econ. 2007;16(12):1359-69.

23. Dunlop DD, Manheim LM, Song J, Chang RW. Gender and ethnic/racial disparities in health care utilization among older adults. J Gerontol Ser B Psychol Sci Soc Sci. 2002;57(4):S221-33.

24. Thorpe JM, Thorpe CT, Kennelty KA, Chewning BA. Depressive symptoms and reduced preventive care use in older adults: the mediating role of perceived access. Med Care. 2012;50(4):302-10

25. Patel K, Kanu M, Liu J, Bond B, Brown E, Williams E, Theriot R, Bailey S, Sanderson M, Hargreaves M. Factors influencing breast cancer screening in low-income African Americans in Tennessee. J Community Health. 2014; 39(5):943-50.

26. Pham HH, Schrag D, Hargraves JL, Bach PB. Delivery of preventive services to older adults by primary care physicians. Jama. 2005;294(4):473-81.

27. Kim ES, Moored KD, Giasson HL, Smith J. Satisfaction with aging and use of preventive health services. Prev Med. 2014;69:176-80.

28. Berkman ND, Sheridan SL, Donahue KE, Halpern DJ, Viera A, Crotty K, Holland A, Brasure M, Lohr KN, Harden E. Health literacy interventions and outcomes: an updated systematic review. Evid Rep Technol Assess. 2011:199:1-941.

29. Tuthill EL, McGrath JM, Graber M, Cusson RM, Young SL. Breastfeeding Self-efficacy: A Critical Review of Available Instruments. J Human Lactation. 2015.

30. Kroll T, Kehn M, Ho PS, Groah S. The SCI Exercise Self-Efficacy Scale (ESES): development and psychometric properties. Int J Behav Nutr Phys Activ. 2007:4:34

31. Etter JF, Bergman MM, Humair JP, Perneger TV. Development and validation of a scale measuring self-efficacy of current and former smokers. Addiction (Abingdon, England). 2000;95(6):901-13.

32. Nicholas MK. The pain self-efficacy questionnaire: Taking pain into account. Eur J Pain (London, England). 2007:11(2):153-63.

33. Bandura A. Guide for Constructing Self-efficacy Scales. In: Pajares F, Urdan TC editors. Self-efficacy Beliefs of Adolescents. Information Age Publishing; 2006: 307-337

34. Ritter PL, Lorig K. The English and Spanish Self-Efficacy to Manage Chronic Disease Scale measures were validated using multiple studies. J Clin Epidemiol. 2014;67(11):1265-73.

35. Newman AB, Bayles CM, Milas CN, McTigue K, Williams K, Robare JF, Taylor CA, Albert SM, Kuller LH. The 10 keys to healthy aging: findings from an innovative prevention program in the community. J Aging Health. 2010; 22(5):547-66.

36. Robare JF, Bayles CM, Newman AB, Williams K, Milas C, Boudreau R, et al. The "10 keys" to healthy aging: 24-month follow-up results from an innovative community-based prevention program. Health Educ Behav. 2011; 38(4):379-88.

37. Lorig KSA, Ritter P, González V, Laurent D, Lynch J. Outcome Measures for Health Education and other Health Care Interventions. Thousand Oaks CA: Sage Publications; 1996.

38. Schlenk EA, Bilt JV, Lo-Ciganic WH, Jacob ME, Woody SE, Conroy MB, et al. Pilot Enhancement of the Arthritis Foundation Exercise Program with a Healthy Aging Program. Res Gerontol Nurs. 2015;1-10.

39. Fabrigar $L R$, Wegener DT, MacCallum RC, Strahan EJ. Evaluating the Use of Exploratory Factor Analysis in Psycological Research. Psychol Methods. 1999; 4(3):272-99.

40. Costello AB, Osborne J. Best practices in exploratory factor analysis: four recommendations for getting the most from your analysis. Pract Assess Res Eval. 2005, 10(7): Available online: http://pareonline.net/pdf/v10n7.pdf.
41. Pedhazur EJ, Schmelkin LP. Measurement, Design, and Analysis: An Integrated Approach. Hillsdale, N.J: Lawrence Erlbaum Associates; 1991.

42. Kariser HF. An Index of Factorial Simplicity. Psychometrika. 1974;39(1):32-6.

43. Bartlett MS. Tests of Sigficance in Factor analysis. Br J Psychol. 1950;3(2):77-86.

44. Pett MA, Lackey NR, Sullivan JJ. Making Sense of Factor Analysis: The Use of Factor Analysis for Instrument Development in Health Care Research. London: Sage Publications; 2003.

45. Tabachnik BG, Fiddell LS. Using multivariate statistics, 5 edn. Boston: Allyn and Bacon; 2006.

46. Hayton JC, Allen DG, Scarpello V. Factor retention decisions in exploratory factor analysis: A tutorial on parallel analysis. Organ Res Methods. 2004;7:191-205.

47. Cronbach $\perp$. Coefficient alpha and the internal structure of the tests. Psychometrika. 1951:16(3):297-334.

48. Nunnally J, Bernstein I. Psychometric theory. 3rd ed. New York: McGraw Hill; 1994.

\section{Submit your next manuscript to BioMed Central and we will help you at every step:}

- We accept pre-submission inquiries

- Our selector tool helps you to find the most relevant journal

- We provide round the clock customer support

- Convenient online submission

- Thorough peer review

- Inclusion in PubMed and all major indexing services

- Maximum visibility for your research

Submit your manuscript at www.biomedcentral.com/submit 